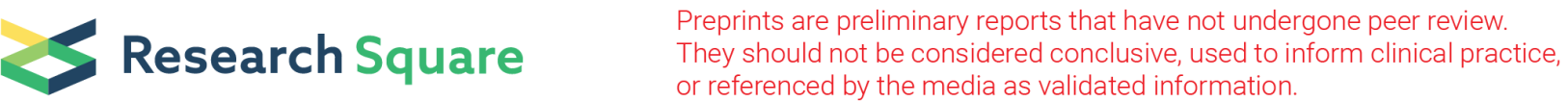

\section{Overexpression of Shinorhizobium Meliloti Flavohemoglobinefficiently Improved Cell Growth and Fatty Acid Biosynthesis in Oleaginous Fungus Mucor Circinelloides}

\section{Huaiyuan Zhang}

Shandong University of Technology

Xinxin Kang

Ocean University of China

Ruixue Wang

Shandong University of Technology

Feifei Xin

Shandong University of Technology

Yufei Chang

Shandong University of Technology

Yingtong Zhang ( $\nabla$ ytzhang@jaas.ac.cn )

Jiangsu Academy of Agricultural Sciences https://orcid.org/0000-0003-2935-7970

Yuanda Song

Shandong University of Technology

\section{Research Article}

Keywords: Fatty acid biosynthesis, Flavohemoprotein, Hemoprotein, Mucor circinelloides

Posted Date: December 2nd, 2021

DOI: https://doi.org/10.21203/rs.3.rs-1109568/v1

License: (c) (i) This work is licensed under a Creative Commons Attribution 4.0 International License.

Read Full License 


\section{Abstract}

Oxygen availability is a limiting factor for lipid biosynthesis in eukaryotic microorganisms. Two bacterial hemoglobins from Vitreoscilla sp. (VHb) and Shinorhizobium meliloti (SHb), which could deliver the oxygen to the respiratory chain to produce more ATP, were introduced into Mucor circinelloides to alleviate oxygen limitation, thereby improving cell growth and fatty acid production. VHb and $\mathrm{SHb}$ genes were integrated into the $M$. circinelloides MU402 genome through homologous recombination, and their protein expression was verified by carbon monoxide difference spectrum (CO-difference spectrum)analysis. SHbexpressing strain showed higher biomass than $\mathrm{VHb}$-expressing strain. The biomass of the SHbexpressing strain was increased by about $50 \%$ and the total fatty acid (TFA) content was as high as $15.7 \%$ of the dry cell weight which was about $40 \%$ higher than that of the control strain in flask conditions. In the fermenter, the maximum biomass and TFA content was obtained in SHb-expressing strains, with the biomass being $12.1 \mathrm{~g} / \mathrm{L}$ and the TFA being $21.1 \%$ of the dry cell weight. VHb and SHb expression also affected the fatty acid composition with the proportion of polyunsaturated fatty acids being increased. Over-expression of bacterial hemoglobins, especially SHb increased cell growth and TFA content in M. circinelloides at low and high aeration, suggesting that $\mathrm{SHb}$ is better than $\mathrm{VHb}$ in improving the fatty acid production in oleaginous microorganisms.

\section{Introduction}

Oleaginous microorganisms are able to accumulate lipid to $>20 \%$ of their dry cell weight. Microbial lipid is believed to a promising raw material for biofuel production or an alternative source for polyunsaturated fatty acids (Adrio 2017; Ageitos et al. 2011; Hill et al. 2006). The typical oleaginous microorganisms include microalgae, fungi and yeasts. So far, the biochemical mechanisms of lipid accumulation in oleaginous microorganisms have been deeply explored to improve lipid production (Zhang et al. 2014; Wynn et al. 2001). The intracellular lipid content in oleaginous microorganisms can be increased to approach their theoretical level by genetical modification (Blazeck et al. 2014; Qiao et al. 2017). However, the fermentation technology can affect their productivity, particularly the level of dissolved oxygen (D0) in the medium (Yen and Zhang 2011; Zhang et al. 2019). Oxygen supply is an important parameter in aerobic fermentation, since it participates in numerous intracellular biochemical reactions. The Krebs cycle, glycolysis, and de novo fatty acid synthesis may require $\mathrm{O}_{2}$ supply for the production of ATP via oxidative phosphorylation (Mannix et al. 1995; Martin et al. 2002). Low oxygen levels can reduce ATP production, and influence the intracellular biochemical reactions. Thus, sufficient oxygen availability during fermentation process could be a powerful process to enhance lipid production in oleaginous microorganisms.

The increased aeration and addition of surfactants are still the most common approaches to increase the concentrations of DO during the fermentation process. However, these approaches require high energy consumption or more specialized equipment. Previously, a bacterial hemoglobin, Vitreoscilla hemoglobin $(\mathrm{VHb})$, has been introduced into a cell by genetic modification, for improving oxygen transfer in hypoxia conditions (Kallio et al. 1994). VHb is a well-characterized bacterial hemoglobin, owing to its effective 
intracellular oxygen transfer to help aerobic organism adapt to the low oxygen conditions (Frey and Kallio 2003; Khosla et al. 1990). VHb has been used to alleviate oxygen-limiting conditions by improving oxygen supply, protein expression, cellular growth, and metabolic production during microbial fermentations. VHb-expressing Pichia pastoris, produced more lipase than the control cells under oxygen-limited conditions (Wang et al. 2012). Over-expression of VHb in Schwanniomyces occidentalis increased total protein secretion and alpha-amylase production (Suthar and Chattoo 2006). The mutant Mortierella alpina $\mathrm{VHb}-20$, expressing a codon optimized $\mathrm{VHb}$ gene, has 4-fold and 8-fold increases in total lipid and arachidonic acid (ARA) yields, respectively, compared to control strains under microaerobic environments. In addition, under normal conditions, the level of ARA was 1.6-fold higher than that of wild-type (Zhang et al. 2017). A VHb-expressing Aurantiochytrium sp. mutant showed $44 \%$ increase in total fatty acid (TFA) and 9-fold elevated of astaxanthin concentrations at low DO conditions (Suen et al. 2014). The expression of $\mathrm{VHb}$ in Yarrowia lipolytica remarkably improved the biomass, TFA content and citrate secretion under various DO conditions compared with control strains (Zhang et al. 2019). In addition to a common increase in DO levels of microbial fermentations for enhanced cell growth, the production of metabolites can also be improved by VHb during high cell-density fermentation (Pablos et al. 2011).

Flavohemoprotein shares high degrees of sequence and structural similarities in its globin domain with hemoglobin, and its expression have more positive influence on cell growth than $\mathrm{VHb}$ expression. One flavohemoprotein from Alcaligenes eutrophus was expressed in Escherichia coli, which led to $50 \%$ higher final cell density than VHb-expressing strain (Frey et al. 2000). Another flavohemoglobin (SHb), isolated from Sinorhizobium meliloti strain 1021, has a type globin domain fused with ferredoxin reductaselike FAD-binding and NAD(P)-binding domain (Lira-Ruan et al. 2003). Streptomyces lividans TK24 overexpressing $\mathrm{SHb}$ produced more secondary metabolites than $\mathrm{VHb}$-transformant, because $\mathrm{SHb}$ expression could activate the pentose phosphate pathway by regulating oxidative stress and increasing NADPH levels (Kim et al. 2007).

The filamentous fungus Mucor circinelloides has received growing attention from industrial field, as it can accumulate gamma linolenic acid (GLA) by more than $30 \%$ of the TFA content (Ratledge 2004). Now, M. circinelloides is considered as a model organism for studying lipid accumulation in oil producing filamentous fungi due to its clear genetic background and perfect molecular biology tools (Vellanki et al. 2018). Accordingly, to attenuate oxygen limitation, improve cell growth and promote the yields of lipid production in $\mathrm{M}$. circinelloides, $\mathrm{VHb}$ and $\mathrm{SHb}$ genes were introduced into this fungus genome by homologous recombination, and then the influence of $\mathrm{VHb}$ and $\mathrm{SHb}$ overexpression on cellular growth and fatty acid production was investigated in this study.

\section{Materials And Methods}

\section{Strains, plasmids and culture conditions}

For plasmid amplification, E. coli TOP10 competent cells were cultured in Lysogeny Broth (LB) containing $100 \mu \mathrm{g}$ of ampicillin $/ \mathrm{mL}$ and maintained at $37^{\circ} \mathrm{C}$ with constant shaking. Mucor circinelloides MU502 
(uridine auxotroph) was the recipient strain in transformation experiments for $\mathrm{VHb}$ and $\mathrm{SHb}$ genes overexpression. The $\mathrm{VHb}$ and $\mathrm{SHb}$ genes were cloned from plasmids pIB139-vhb and pIB139-sm (Mo et al. 2016). The MMC and YPG medium were supplemented with $200 \mu \mathrm{g}$ uridine/ $\mathrm{mL}$ if necessary, and used to culture strains at $26^{\circ} \mathrm{C}$ (Nicolas et al. 2007). The pH of media was fixed at 3.0 and 4.5 for colonial and mycelial growth, respectively.

Mutant strains and control strains were cultivated in 1-L baffled flasks supplemented with K\&R medium $(200 \mathrm{~mL})$, modified to contain $80 \mathrm{~g}$ glucose $/ \mathrm{L}$ and $2 \mathrm{~g}$ ammonium tartrate $/ \mathrm{L}$ at $28^{\circ} \mathrm{C}$ with continuous shaking (150 rpm) for $96 \mathrm{~h}$ (Kendrick and Ratledge 1992). Fermentation was carried out a $2 \mathrm{~L}$ fermenter containing modified K\&R medium $(1.5 \mathrm{~L})$ with inoculation at $10 \%(\mathrm{v} / \mathrm{v})$. The fermentation process was maintained at $28^{\circ} \mathrm{C}$ with continuous stirring $(700 \mathrm{rpm})$ and aeration $(0.2$ and $0.5 \mathrm{vvm})$. The pH was fixed at 6.0 by automatically adding $1 \mathrm{M} \mathrm{HCl}$ or $1 \mathrm{M} \mathrm{KOH}$.

\section{$\mathrm{VHb}$ - and $\mathrm{SHb}$ - expressing strains construction}

The $\mathrm{VHb}$ and $\mathrm{SHb}$ genes were cloned into expression plasmid pMAT1552 for protein expression. The plasmid pMAT1552, containing the $M$. circinelloides pyrG gene surrounded down- and up-stream by $1 \mathrm{~kb}$ CarRP sequences, was employed for the construction of $\mathrm{VHb}$ and $\mathrm{SHb}$ genes overexpressing plasmids. The VHb and SHb genes were amplified using their primers with plasmids pIB139-vhb and pIB139-sm as the PCR template (Mo et al. 2016), which composes of 30-bp homologous sequences in pMAT1552 containing $\mathrm{Xhol}$ restriction sites. The PCR fragments were purified and cloned into the pMAT1552 at restriction endonucleases Xho I to yield pMAT1552-VHb and pMAT1552-SHb (In-Fusion HD Cloning kits, TaKaRa). The finished plasmids were linearized by restriction endonuclease EcoRI and $S r f I$, and then transformed into $M$. circinelloides cells through electroporation as described previously (Zhao et al. 2016), with the initial plasmid as the control. The transformants were screened by colony color and then subjected to PCR amplification. All the right transformants were named McVHb (VHb-expressing), McSHb (SHb-expressing) and Control strains.

\section{Gene expression and CO-difference spectrum analysis}

$\mathrm{McVHb}$ (VHb-expressing), McSHb (SHb-expressing) and the control mutant strains were cultured in modified K\&R medium for 96 hours. Then, the mycelia were harvested by filtration, ground under liquid nitrogen, and dissolved in lysis buffer containing glycerol (5\%), EDTA (1 mM), sodium phosphate (50 $\mathrm{mM}), \mathrm{pH}$ 7.4. The cell lysate of expressed strains and control strains were centrifuged and supernatants were used for carbon monoxide (CO)-difference spectral analysis. The supernatants were divided into two aliquots and treated with sodium dithionite $\left(\mathrm{Na}_{2} \mathrm{~S}_{2} \mathrm{O}_{4}, 2.5 \mathrm{mg} / \mathrm{mL}\right)$ to reduce the expressed $\mathrm{VHb}$ and $\mathrm{SHb}$ protein. Afterwards, $\mathrm{CO}$ gas was bubbled through an aliquot to coordinate $\mathrm{SHb}$ and $\mathrm{VHb}$. The aliquot without $\mathrm{CO}$ exposure was used as a calibration control. CO-difference spectra were measured in the range of 400-470 nm using an UV-VIS spectrophotometer (SHIMADZU, Kyoto, Japan) according to previous methods (Liu and Webster 1974; Dikshit and Webster 1988). 
After fermentation, the cultivation was separated by filtering through a Buchner funnel at low pressure, and the filter liquor was used for determination of glucose and nitrogen concentration. The glucose oxidase Perid-test kit (Shanghai Rongsheng Biotech Co., Ltd) was used to measure the concentrations of glucose in the culture. Meanwhile, the indophenol method was employed to determine ammonium concentrations (Chaney and Marbach 1962). After washing with distilled water for 3 times, the mycelium was harvested on a weighed filter paper, followed by freeze-drying. The weight of the biomass was evaluated gravimetrically.

\section{Determination of TFA content and fatty acid compositions}

TFA was extracted from $20 \mathrm{mg}$ mycelia with methanol/chloroform (1:2, v/v), then methylated with 10\% $(\mathrm{w} / \mathrm{w})$ methanolic $\mathrm{HCl}$ for $3 \mathrm{~h}$ at $60^{\circ} \mathrm{C}$ and dissolved in $\mathrm{n}$-hexane with pentadecanoic acid (15:0) as an internal standard. The content and composition of TFAs were assessed by GC with DB-Waxetr column (30 $\mathrm{m} \times 0.32 \mathrm{~mm}, 0.25 \mu \mathrm{m}$ film thickness). The following program was set: $3 \mathrm{~min}$ at $120^{\circ} \mathrm{C}$, ramped to $200^{\circ} \mathrm{C}$ at $5^{\circ} \mathrm{C} / \mathrm{min}$, ramped to $220^{\circ} \mathrm{C}$ at $4^{\circ} \mathrm{C} / \mathrm{min}$, and held for $2 \mathrm{~min}$ (Zhang et al. 2018).

\section{Statistical analysis}

Statistical tests were conducted with SPSS v16.0 (SPSS Inc., IL, USA). All values were obtained from 3 independent experiments, and were presented as mean \pm standard error of the mean. The difference between two groups was determined by Student's $t$ test, and $P<0.05$ was regarded as statistically significant.

\section{Results}

\section{Construction of $\mathrm{VHb}$ - and $\mathrm{SHb}$-expressing strains}

The plasmid pMAT1552 with pyrG gene was chosen for VHb and SHb expression in M. circinelloides. This plasmid was chosen because of its designed homologous fragment, CarRP, which could be integrated into the chromosome via homologous recombination (Fig. 1). CarRP gene encodes lycopene cyclase/phytoene synthase, which is a key enzyme in $\beta$-carotene biosynthesis. ${ }^{29}$ When $\mathrm{VHb}$ and $\mathrm{SHb}$ expression cassettes were integrated into the genomic DNA, the CarRP gene was broken and $\beta$-carotene biosynthesis was shutoff. Therefore, the correct mutants with homologous recombination were obtained by observing the color of single colonies. The transformants were screened until the whole colony turned white, because of multiple nucleuses in the fungus cell (Vellanki et al. 2018). All transformants were cultured in K\&R medium and genomic DNA was extracted for PCR verification. The confirmed McVHb (VHb-expressing), McSHb (SHb-expressing) mutant strains, and the control strains were used for further analysis.

The characteristics of $\mathrm{VHb}$ and $\mathrm{SHb}$ protein and their expression level in M. circinelloides 
$\mathrm{VHb}$ and $\mathrm{SHb}$ proteins, which belong to the hemoglobin family but originate from different species, can transfer oxygen for physiological activity. However, the number of amino acid residues of SHb (403 aa) is about three times larger than that of $\mathrm{VHb}(146 \mathrm{aa})$. Alignment with $\mathrm{VHb}$ sequence showed that $\mathrm{SHb}$ contains two additional, highly conserved motifs: oxido-reductase FAD-binding and NAD(P)-binding domain (the sequences), except the heme-binding domain (Fig. 2A).

The expression of $\mathrm{VHb}$ and $\mathrm{SHb}$ in $\mathrm{M}$. circinelloides was verified by CO-difference spectral analysis (Fig. 2B). On treatment with $\mathrm{CO}$, there was a typical peak at about $419 \mathrm{~nm}$ in mutant strains with $\mathrm{VHb}$ or $\mathrm{SHb}$ expression, whereas the control strain did not exhibit this peak, demonstrating that active $\mathrm{SHb}$ or $\mathrm{VHb}$ was successfully expressed in $M$. circinelloides mutant strains.

\section{Effects of $\mathrm{VHb}$ and $\mathrm{SHb}$ expression on cellular growth and TFA content in M. circinelloides in flask}

The transformants and the control strains were cultivated in flasks with glucose as a carbon source, to assess the effects of $\mathrm{VHb}$ and $\mathrm{SHb}$ expression on the biomass and TFA content in $M$. circinelloides (Fig. 3). Compared to the control strains, the biomass were improved in $\mathrm{VHb}$ - and $\mathrm{SHb}$ - expressing strains, and $\mathrm{SHb}$-expressing strains had larger amount of biomass than $\mathrm{VHb}$-expressing strains. The biomass of $\mathrm{SHb}$-expressing strain No 1 reached a maximum of $9.8 \mathrm{~g} / \mathrm{l}$, which was $50 \%$ higher than that of control strains (Fig. 3A). The biomass showed a significant difference among the transformants with the same gene integration, however, there was only a slight difference in TFA content (Fig. 3B). Like the results of biomass, both $\mathrm{VHb}$ and $\mathrm{SHb}$ expression in $\mathrm{M}$. circinelloides led to increased TFA content. TFA content in SHb-expressing strain number 1 was up to $15.7 \%$ of dry cell weight, which was about $40 \%$ higher than in control strains. There was also a better impact on the TFA content in SHb-expressing strains than VHbexpressing strains.

\section{Verification of the effect of $\mathrm{VHb}$ and $\mathrm{SHb}$ expression on cellular growth of $\mathrm{M}$. circienlloides grown in fermenter}

$\mathrm{VHb}$ and $\mathrm{SHb}$ expression had positive influence on cell proliferation and lipid biosynthesis in $M$. circinelloides cultivated in flask. Since the fermentation condition of the flask was unstable and the ventilation was limited, the fermenter was used to verify the results obtained in flask conditions. The mutant strains were cultivated in a fermenter at 0.2 and $0.5 \mathrm{vvm}$, and the samples were collected for residual glucose concentration, ammonia concentration, biomass, and TFA content determination.

The aeration rate is an extremely important parameter for cell growth of $M$. circinelloides. At the aeration rate of $0.2 \mathrm{vvm}$, the biomass of the control and the VHb-expressing transformants was up to $\sim 60 \%$ lesser (from $\sim 8.0 \mathrm{~g} / \mathrm{L}$ to $\sim 5.0 \mathrm{~g} / \mathrm{L}$ ) than the biomass at the relatively high aeration rate $(0.5 \mathrm{vvm})$. However, the cell growth in SHb-expressing transformants was not virtually inhibited at low oxygen condition $(0.2 \mathrm{vvm})$. There was significant difference among the mutant strains, the maximum biomass of $\mathrm{McSHb}$ was $12.1 \mathrm{~g} / \mathrm{L}$ (Fig. 4), which was higher than the control and the VHb-expressing transformants, especially at low oxygen conditions $(0.2 \mathrm{vvm})$. Therefore, the expression of SHb clearly promoted cell growth in $M$. circinelloides. 
During fermentation, residual glucose and ammonia concentration was measured to monitor the nutrition condition in the medium. The results showed that the rate of glucose consumption in strain McSHb with high aeration $(0.5 \mathrm{vvm})$ slowed down, however the rate of ammonia consumption became faster compared to the control strain and $\mathrm{McVHb}$. When these mutant strains were cultivated at low aeration $(0.2 \mathrm{vvm})$, there was a same trend in the rate of ammonia consumption among the transformants, while the rate of glucose consumption showed no difference between the control strain and $\mathrm{McVHb}$, and the residual glucose of strain $\mathrm{McSHb}$ was lower than these two strains (Fig. 5).

\section{Effects of $\mathrm{VHb}$ and $\mathrm{SHb}$ expression on TFA content and composition of M. circienlloides grown in fermenter}

When these transformants were cultivated in fermenter at high aeration condition ( $0.5 \mathrm{vvm})$, hemoglobin expression led to improvement of the TFA content. The TFA content of SHb-expressing strain was up to $21.1 \%$ of dry cell weight, increased by $35.2 \%$ compared to that of control strains. However, the TFA content of VHb-expressing strain was only increased by $12.8 \%$, further. The TFA content of these mutant strains, at low aeration rate $(0.2 \mathrm{vvm})$, was significantly lower than at high aeration rate. The TFA content of $\mathrm{VHb}$-expressing strain markedly reduced (from 17.6-14.3\%) at low aeration rate, whereas TFA content of McSHb was only weakly affected. Irrespective of the aeration rate, the TFA content of McSHb still remained at a relatively high level, and the maximum lipid content of $\mathrm{McSHb}$ was more than $20 \%$ of the dry cell weight (Fig. 6).

The fatty acid profile of $\mathrm{VHb}$ - and SHb-expressing transformants was also analyzed (Table 1). The profile revealed the main contributors to the fatty acid content of triacylglyceride were saturated fatty acid (C16:0), oleic acid (C18:1) and polyunsaturated fatty acids (C18:2 and C18:3). Stearic acid (C18:0) occured in a lower amount and measurable tetradecanoic acid (C14:0) was detected. The fatty acids of $\mathrm{VHb}$ - and $\mathrm{SHb}$-expressing transformants presented similar values with the control strain when cultured in fermenter, and $\mathrm{SHb}$ expression resulted in more change in fatty acid profile than VHb expression in $M$. circinelloides. The SHb expression led to an increase in polyunsaturated fatty acids constituents and a decrease in the monounsaturated fatty acid relative to the control strain, while no obvious saturated fatty acid change was observed in two fermenter conditions. The proportion of polyunsaturated fatty acids in $\mathrm{McSHb}$ was clearly higher than $\mathrm{McVHb}$ and the proportion of $\mathrm{C} 18: 3$ in SHb-expressing strain was up to $22.3 \%$ of TFA.

\section{Discussion}

Oleaginous microorganisms can synthesize intracellular fatty acids to $>20 \%$ of their dry cell weight by using series of carbon source. The pathways for de novo fatty acid biosynthesis in oleaginous microorganisms have been fully mapped out (Ageitos et al. 2011). Two substrates, NADPH and acetyl$\mathrm{CoA}$, are required for fatty acid synthesis in all organisms. At present, many metabolic engineering processes are carried out to improve the supply of substrates for producing more fatty acids in oleaginous microorganisms. Along with these substrates, the biochemical pathways of fatty acid synthesis also need energy supply. ATP, the main energy donor in the cells, is mainly provided by 
oxidative phosphorylation through electron respiratory chain (Mannix et al. 1995; Martin et al. 2002), and $\mathrm{O}_{2}$ availability is one of the main factors for ATP production. $\mathrm{VHb}$, an oxygen-binding protein with extremely high oxygen dissociation rate, can enhance DO diffusion especially in microaerophilic conditions. More $\mathrm{O}_{2}$ delivery to cytochrome $d$ and $o$ complex, can improve the activity of the respiratory chain. This was demonstrated in VHb-expressing Saccharomyces cerevisiae and E. coli (Khosla et al. 1990; Chen et al. 1994). Consequently, the relative shift in respiratory chain activities could improve the proton-pumping efficiency, extruding protons for ATPase complexes to generate ATP. Hence, VHb overexpressing has been confirmed to be an efficient way for improving the fatty acid production in bacteria or fungi microbial fermentations. VHb-expressing E. coli mutant accumulated $30 \%$ and $70 \%$ higher amounts of biomass and free fatty acids, respectively, with comparable amount of glucose consumption compared with wild-type strain (Liu et al. 2017). The heterologous expression of VHb in Aurantiochytrium $s p$. mutant exhibited $44 \%$ and 9 -fold higher levels of TFA and astaxanthin than that of wild-type strain in an aerobic environment (Suen et al. 2014). Moreover, the codon-optimized expression of VHb gene showed 8- and 4-fold increases in ARA and total lipid contents compared with Mortierella alpina wild-type strain under microaerobic conditions, and a 1.6-fold increase in ARA yield under standard growth conditions (Zhang et al. 2017). In the present work, a similar result was obtained. The TFA content and biomass of $M$. circinelloides increased because of $\mathrm{VHb}$ expression, irrespective of the aeration rate.

The hemoglobin domain of flavohemoprotein has high degrees of sequence and structural similarities with that of $\mathrm{VHb}$. Thus, flavohemoprotein, like $\mathrm{VHb}$, also had been applied to reduce the detrimental effect of oxygen limitation on microorganisms. The upregulated expression of $\mathrm{VHb}$ and flavohemoglobin genes in Aureobasidium melanogenum P16 could render to overproduce the pullulan concentrations, microbial production and glucose consumption compared with the wild-type strain P16 (Xue et al. 2019). However, $\mathrm{SHb}$ exhibited two extra domains, FAD-binding and NAD(P)-binding domain, which had more positive influence on cell growth and metabolite synthesis than $\mathrm{VHb}$. The hemoglobin domains of flavohemoprotein and $\mathrm{VHb}$ shares of $51 \%$ sequence homology in the gram-negative, hydrogen-oxidizing bacteria Alcaligenes eutrophus. Furthermore, the expression cassettes encoding amino-terminal hemoglobin (FHPg), FHP, VHb or VHb-FAD-NAD activities were constructed. Compared with VHb, the VHbFAD-NAD and FHP could increase the final cell densities of wild-type E. coli about $75 \%$ and 50 , respectively (Frey et al. 2000). Another flavohemoprotein from Sinorhizobium meliloti, SHb, also had been proved that its expression in Streptomyces lividans TK24 by genetic engineering was superior to VHb for biomass production and metabolic regulation (Kim et al. 2007). Our results showed that the biomass of $\mathrm{SHb}$-expressing strain was markedly increased by approximately $35 \%$ at high aeration rate and by approximately $50 \%$ at low aeration rate compared to the $\mathrm{VHb}$-expressing strain.

A similar result was also found that SHb-expressing Streptomyces actuosus in our group led to higher nosiheptide production than a VHb-expressing strain (Mo et al. 2016). SHb expression could enhance the NADPH supply, one substrate of fatty acid biosynthesis, and it was rightly suited for the production of fatty acids in oleaginous microorganisms. Previous studies have found that NADPH supply was a limiting factor for fatty acid accumulation in oleaginous microorganisms, and many molecular biological 
evidences had proved it. The overexpression of $\mathrm{NADP}^{+}$-dependent malic enzymes in Rhodococcus jostii RHA1 and Rhodococcus opacus PD630 strains grown on glucose could elevate total NADP ${ }^{+}$-malic enzyme level and showed 1.9-fold increase in TFA production, without affecting the cell biomass (Hernandez and Alvarez 2019). Glucose-6-phosphate dehydrogenase enzyme level towards NADPH generation was increased by 2.19-fold in the engineered microalgae Chlorella pyrenoidosa. Lipidomic analysis revealed a 3.09-fold increase in total lipid content in the engineered strains, and its yields gradually elevated during the growth phase and remained constant at the stationary phase (Xue et al. 2019). It had been proved that the improvement of NADPH supply could increase TFA production in $M$. circinelloides. In this study, heterologous $\mathrm{SHb}$ expression in $M$. circinelloides enhanced the pentose phosphate pathway and increased the production of NADPH for biosynthesis, in turn positively inspired the cellular growth and the fatty acid production.

In a word, to improve the fermentative DO condition of oleaginous fungus $M$. circinelloides, VHb and SHb genes were successfully expressed by homologous recombination and it was found both $\mathrm{VHb}$ and $\mathrm{SHb}$ expression could increase the cell growth and TFA content at either high aeration or low aeration. Furthermore, SHb expression exhibited more positive influence on cell growth and TFA content than VHb expression in $M$. circinelloides, especially at low aeration.

\section{Declarations}

Acknowledgements: This work was supported by National Natural Science Foundation of China (No. 31972851), Natural Science Foundation of Jiangsu Province (Grant No. BK20190265) and Research project of Yiyuan Industrial Technology Research Institute (platform).

Conflict of interest: All authors declare that they have no competing interests.

Ethical Statement: This article does not contain any studies with human participants or animals performed by any of the authors.

\section{References}

1. Adrio JL (2017) Oleaginous yeasts: Promising platforms for the production of oleochemicals and biofuels. Biotechnol Bioeng 114:1915-1920

2. Ageitos JM, Vallejo JA, Veiga-Crespo P, Villa TG (2011) Oily yeasts as oleaginous cell factories. Appl Microbiol Biotechnol 90:1219-1227

3. Blazeck J, Hill A, Liu L, Knight R, Miller J, Pan A, Otoupal P, Alper HS (2014) Harnessing Yarrowia lipolytica lipogenesis to create a platform for lipid and biofuel production. Nat Commun 5:3131

4. Chaney AL, Marbach EP (1962) Modified reagents for determination of urea and ammonia. Clin Chem 8:130-132

5. Chen W, Hughes DE, Bailey JE (1994) Intracellular expression of Vitreoscilla hemoglobin alters the aerobic metabolism of Saccharomyces cerevisiae. Biotechnol Prog 10:308-313 
6. Dikshit KL, Webster DA (1988) Cloning, characterization and expression of the bacterial globin gene from Vitreoscilla in Escherichia coli. Gene 70:377-386

7. Frey AD, Bailey JE, Kallio PT (2000) Expression of Alcaligenes eutrophus flavohemoprotein and engineered Vitreoscilla hemoglobin-reductase fusion protein for improved hypoxic growth of Escherichia coli. Appl Environ Microbiol 66:98-104

8. Frey AD, Kallio PT (2003) Bacterial hemoglobins and flavohemoglobins: versatile proteins and their impact on microbiology and biotechnology. FEMS Microbiol Rev 27:525-545

9. Hernandez MA, Alvarez HM (2019) Increasing lipid production using an NADP(+)-dependent malic enzyme from Rhodococcus jostii. Microbiology 165:4-14

10. Hill J, Nelson E, Tilman D, Polasky S, Tiffany D (2006) Environmental, economic, and energetic costs and benefits of biodiesel and ethanol biofuels. Proc Natl Acad Sci 103:11206-11210

11. Kallio PT, Kim DJ, Tsa PS, Bailey JE (1994) Intracellular expression of Vitreoscilla hemoglobin alters Escherichia coli energy metabolism under oxygen-limited conditions. Eur J Biochem 219:201-208

12. Kendrick A, Ratledge C (1992) Desaturation of polyunsaturated fatty acids in Mucor circinelloides and the involvement of a novel membrane-bound malic enzyme. Eur J Biochem 209:667-673

13. Khosla C, Curtis JE, DeModena J, Rinas U, Bailey JE (1990) Expression of intracellular hemoglobin improves protein synthesis in oxygen-limited Escherichia coli. Nat Biotechnol 8:849-853

14. Kim YJ, Sa SO, Chang YK, Hong SK, Hong YS (2007) Overexpression of Shinorhizobium meliloti hemoprotein in Streptomyces lividans to enhance secondary metabolite production. J Microbiol Biotechnol 17:2066-2070

15. Lira-Ruan V, Sarath G, Klucas RV, Arredondo-Peter R (2003) In silico analysis of a flavohemoglobin from Sinorhizobium meliloti strain 1021. Microbiol Res 158:215-227

16. Liu CY, Webster DA (1974) Spectral characteristics and inter conversions of the reduced oxidized, and oxygenated forms of purified cytochrome o. J Biol Chem 249:4261-4266

17. Liu D, Wan N, Zhang F, Tang YJ, Wu SG (2017) Enhancing fatty acid production in Escherichia coli by Vitreoscilla hemoglobin overexpression. Biotechnol Bioeng 114:463-467

18. Mannix ET, Boska MD, Galassetti P, Burton G, Manfredi F, Farber MO (1995) Modulation of ATP production by oxygen in obstructive lung disease as assessed by 31P-MRS. J Appl Physiol 78:22182227

19. Martin M, Macias M, Leon J, Escames G, Khaldy H, Acuna-Castroviejo D (2002) Melatonin increases the activity of the oxidative phosphorylation enzymes and the production of ATP in rat brain and liver mitochondria. Int J Biochem Cell Biol 34:348-357

20. Mo Q, Zhang H, Liu Q, Tang X, Zhao L, Zan X, Song Y (2016) Enhancing nosiheptide production in Streptomyces actuosus by heterologous expression of haemoprotein from Sinorhizobium meliloti. Lett Appl Microbiol 62:480-487

21. Nicolas FE, de Haro JP, Torres-Martinez S, Ruiz-Vazquez RM (2007) Mutants defective in a Mucor circinelloides dicer-like gene are not compromised in siRNA silencing but display developmental 
defects. Fungal Genet Biol 44:504-516

22. Pablos TE, Mora EM, Le Borgne S, Ramirez OT, Gosset G, Lara AR (2011) Vitreoscilla hemoglobin expression in engineered Escherichia coli: improved performance in high cell-density batch cultivations. Biotechnol J 6:993-1002

23. Qiao K, Wasylenko TM, Zhou K, Xu P, Stephanopoulos G (2017) Lipid production in Yarrowia lipolytica is maximized by engineering cytosolic redox metabolism. Nat Biotechnol 35:173-177

24. Ratledge C (2004) Fatty acid biosynthesis in microorganisms being used for Single Cell Oil production. Biochimie 86:807-815

25. Suen YL, Tang H, Huang J, Chen F (2014) Enhanced production of fatty acids and astaxanthin in Aurantiochytrium sp. by the expression of Vitreoscilla hemoglobin. J Agric Food Chem 62:1239212398

26. Suthar DH, Chattoo BB (2006) Expression of Vitreoscilla hemoglobin enhances growth and levels of alpha-amylase in Schwanniomyces occidentalis. Appl Microbiol Biotechnol 72:94-102

27. Vellanki S, Navarro-Mendoza MI, Garcia A, Murcia L, Perez-Arques C, Garre V, Nicolas FE, Lee SC (2018) Mucor circinelloides: growth, maintenance, and genetic manipulation. Curr Protoc Microbiol 49:e53

28. Wang X, Sun Y, Shen X, Ke F, Zhao H, Liu Y, Xu L, Yan Y (2012) Intracellular expression of Vitreoscilla hemoglobin improves production of Yarrowia lipolytica lipase LIP2 in a recombinant Pichia pastoris. Enzyme Microb Technol 50:22-28

29. Wynn JP, Hamid AA, Li Y, Ratledge C (2001) Biochemical events leading to the diversion of carbon into storage lipids in the oleaginous fungi Mucor circinelloides and Mortierella alpina. Microbiology 147:2857-2864

30. Xue J, Chen TT, Zheng JW, Balamurugan S, Liu YH, Yang WD, Liu JS, Li HY (2019) Glucose-6Phosphate dehydrogenase from the oleaginous microalga Nannochloropsis uncovers its potential role in promoting lipogenesis. Biotechnol J 15:e1900135

31. Xue SJ, Jiang H, Chen L, Ge N, Liu GL, Hu Z, Chi ZM, Chi Z (2019) Over-expression of Vitreoscilla hemoglobin $(\mathrm{VHb})$ and flavohemoglobin $(\mathrm{FHb})$ genes greatly enhances pullulan production. Int $\mathrm{J}$ Biol Macromol 132:701-709

32. Yen HW, Zhang Z (2011) Effects of dissolved oxygen level on cell growth and total lipid accumulation in the cultivation of Rhodotorula glutinis. J Biosci Bioeng 112:71-74

33. Zhang H, Feng Y, Cui Q, Song X (2017) Expression of Vitreoscilla hemoglobin enhances production of arachidonic acid and lipids in Mortierella alpina. BMC Biotechnol 17:68

34. Zhang H, Kang X, Xiao N, Gao M, Zhao Y, Zhang B, Song Y (2019) Intracellular expression of Vitreoscilla haemoglobin improves lipid production in Yarrowia lipolytica. Lett Appl Microbiol 68:248-257

35. Zhang H, Zhang L, Chen H, Chen YQ, Chen W, Song Y, Ratledge C (2014) Enhanced lipid accumulation in the yeast Yarrowia lipolytica by over-expression of ATP:citrate lyase from Mus musculus. J Biotechnol 192 PtA:78-84 
36. Zhao L, Canovas-Marquez JT, Tang X, Chen H, Chen YQ, Chen W, Garre V, Song Y, Ratledge C (2016) Role of malate transporter in lipid accumulation of oleaginous fungus Mucor circinelloides. Appl Microbiol Biotechnol 100:1297-1305

37. Zhang L, Zhang H, Song Y (2018) Identification and characterization of diacylglycerol acyltransferase from oleaginous fungus Mucor circinelloides. J Agric Food Chem 66:674-681

38. Zhang X, Chen J, Wu D, Li J, Tyagi RD, Surampalli RY (2019) Economical lipid production from Trichosporon oleaginosus via dissolved oxygen adjustment and crude glycerol addition. Bioresour Technol 273:288-296

\section{Tables}

Table 1

Fatty acid compositions of $\mathrm{McVHb}, \mathrm{McSHb}$ and the control strains cultivated in fermenter with aeration at $0.5 \mathrm{vvm}$ and $0.2 \mathrm{vvm}$

\begin{tabular}{|llllllll|}
\hline Strains & $\begin{array}{l}\text { Aeration } \\
\text { (vvm) }\end{array}$ & \multicolumn{6}{l}{ Fatty acid profile $(\%, w / w)$} \\
\cline { 3 - 8 } & & C14:0 & C16:0 & C18:0 & C18:1 & C18:2 & C18:3 \\
\hline Control & 0.2 & $2.3 \pm$ & $21.4 \pm$ & $5.9 \pm$ & $33.2 \pm$ & $20.3 \pm 1.5$ & $16.9 \pm$ \\
& & 0.3 & 1.2 & 0.7 & 2.1 & & 1.6 \\
& 0.5 & $2.1 \pm 0.4$ & $20.3 \pm$ & $5.7 \pm$ & $31.3 \pm$ & $21.7 \pm 1.6$ & $18.9 \pm$ \\
& & & 1.5 & 0.5 & 1.6 & & 1.1 \\
\hline Mc- & 0.2 & $1.9 \pm$ & $22.3 \pm$ & $6.3 \pm$ & $30.7 \pm$ & $21.5 \pm$ & $17.3 \pm$ \\
VHb & & 0.2 & 1.7 & 0.7 & 2.5 & 1.4 & 0.5 \\
& 0.5 & $2.0 \pm$ & $21.8 \pm$ & $6.1 \pm$ & $28.2 \pm$ & $21.8 \pm$ & $20.1 \pm$ \\
& & 0.1 & 1.1 & 0.3 & 2.7 & 2.3 & 0.7 \\
\hline Mc- & 0.2 & $2.2 \pm$ & $21.7 \pm$ & $6.0 \pm$ & $26.9 \pm$ & $22.9 \pm$ & $20.3 \pm$ \\
SHb & & 0.4 & 0.8 & 0.6 & 1.9 & 0.4 & 0.4 \\
& 0.5 & $2.4 \pm$ & $20.5 \pm$ & $5.6 \pm$ & $25.1 \pm$ & $24.3 \pm$ & $22.3 \pm$ \\
& & 0.2 & 1.3 & 0.3 & 1.2 & 0.9 & 2.1 \\
\hline
\end{tabular}

\section{Figures}




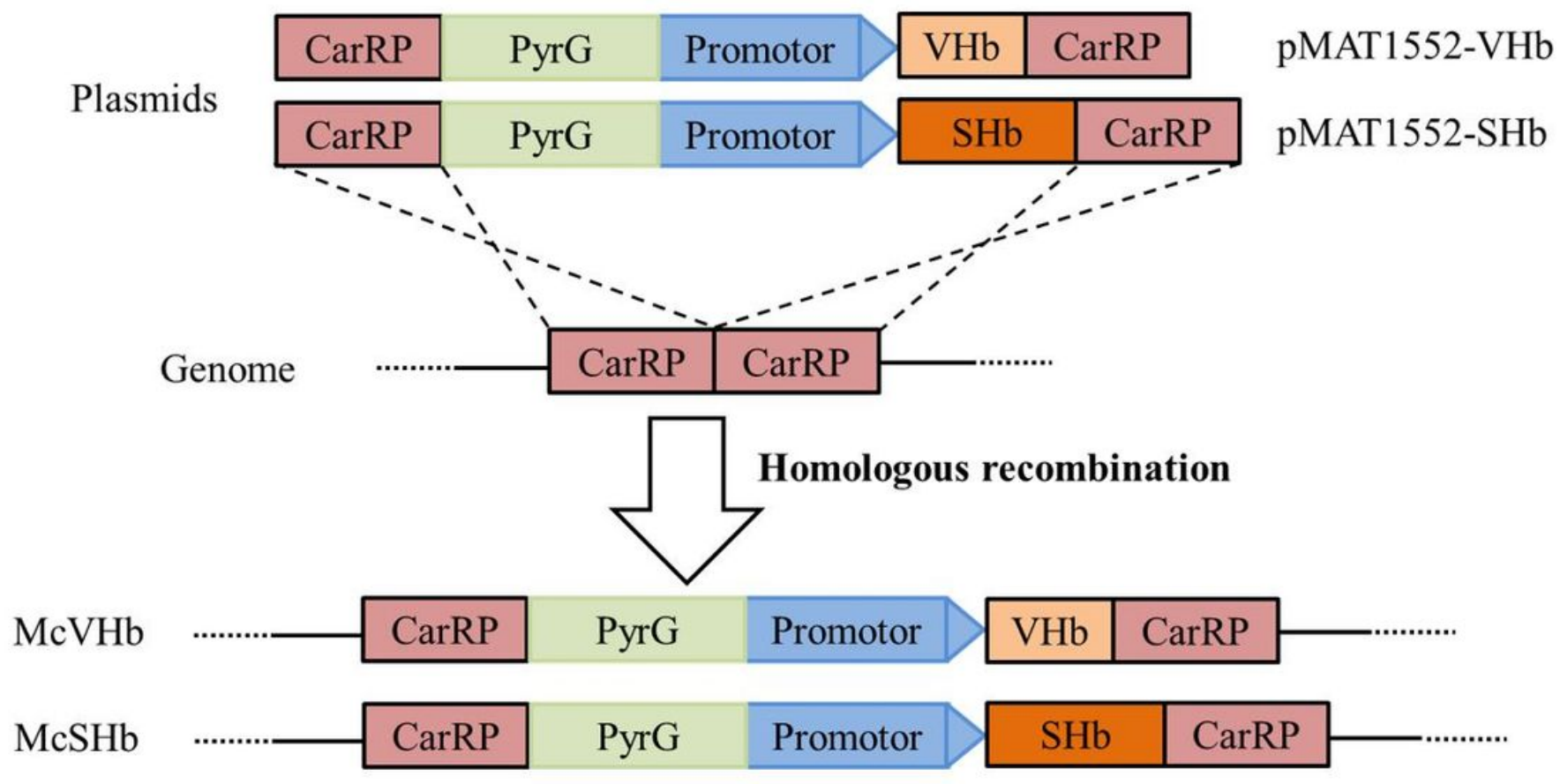

(Fig. 1)

\section{Figure 1}

The construction strategy of VHb- and SHb-expressing strains. The plasmid pMAT1552 for the VHb and $\mathrm{SHb}$ genes expression containing the pyrG gene surrounded down- and up-stream by $1 \mathrm{~kb}$ CarRP sequences, which could be integrated into the chromosome via homologous recombination.

A

SHb MLTQKTKDIVKATAPVLAQHGYAIIQHFYKRUFQAHPELKDIFNMAHERGEQCQALARA 60 VHb MLDQOTINITKATVPVIKEHGVTITTIFYKNLFAKHPEVRPLFDUGROESLEOPKALAVI 60

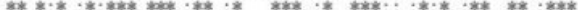

VYAYAANIEVPESLSAVLKDIAHKHASIGVRPEOYPIVGEHLLASIKEVLGDAATDEIIS 120 VLAAAQNIEVLPAILPAVKKIAVKHCQAGVAAAHYPIVGELLGAIKEVLGDAATDDILD 120

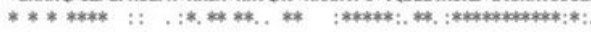

WAQAYGILADILAGIESELYGRSEERAGGTAGTRRFIVREKNPESDVITSFVLEPADCG 180 ATGKAYGVIADVFIQVEADLYAQAVE* **, : * : :**:: : :*:: : * : : *

$\mathrm{SHb}$

PVADFEPCOYTSVAVOVPKLGYQQIROYSLSDSPNGRSYRISVKREDGGLGIPGYVSSLL 240

HDE INVGDEPKLAAPYGNFYIDVSATTPIVL ISGGVGL TPIVSULKKALOTPPRKWFVH 300

GARNSAVHAURORLKEASRTYPDFKL.FIFYDEPLPTDIEGRDYDFAGLVVVEVKDSILL 360

DDADYYICGPVPFIIRUOHDKLLLLGI TEARIHYEVFGPDLFAE* 403
B

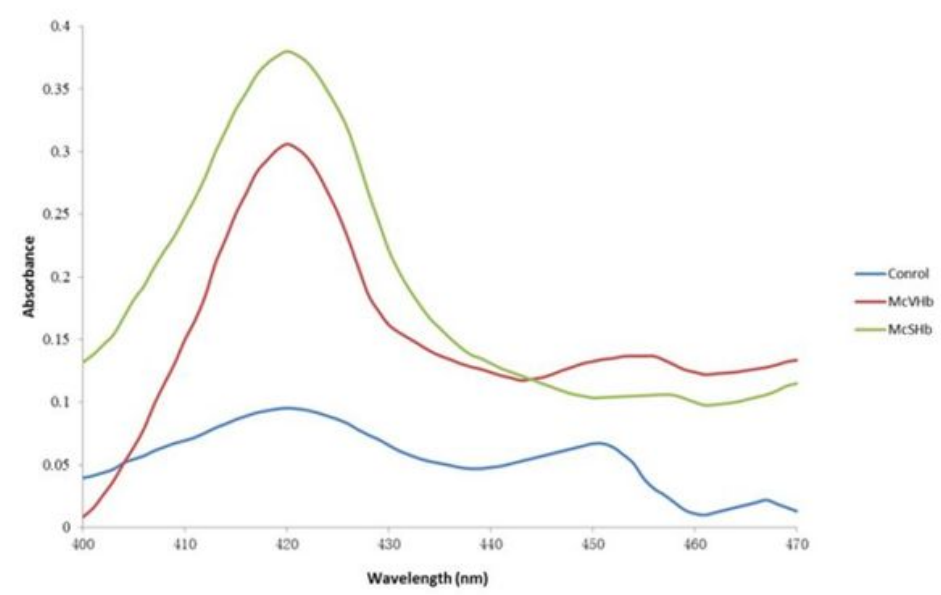

(Fig. 2) 
Figure 2

The amino acid sequence alignment $(\mathrm{A})$ of $\mathrm{VHb}$ and $\mathrm{SHb}$ and their protein expression $(\mathrm{B})$ in $\mathrm{M}$. circinelloides. The amino acid sequence of $\mathrm{VHb}$ and $\mathrm{SHb}$ were aligned by Clustal Omega, and the protein expression of $\mathrm{SHb}$ and $\mathrm{VHb}$ was analyzed by CO-difference spectrum described in Methods.

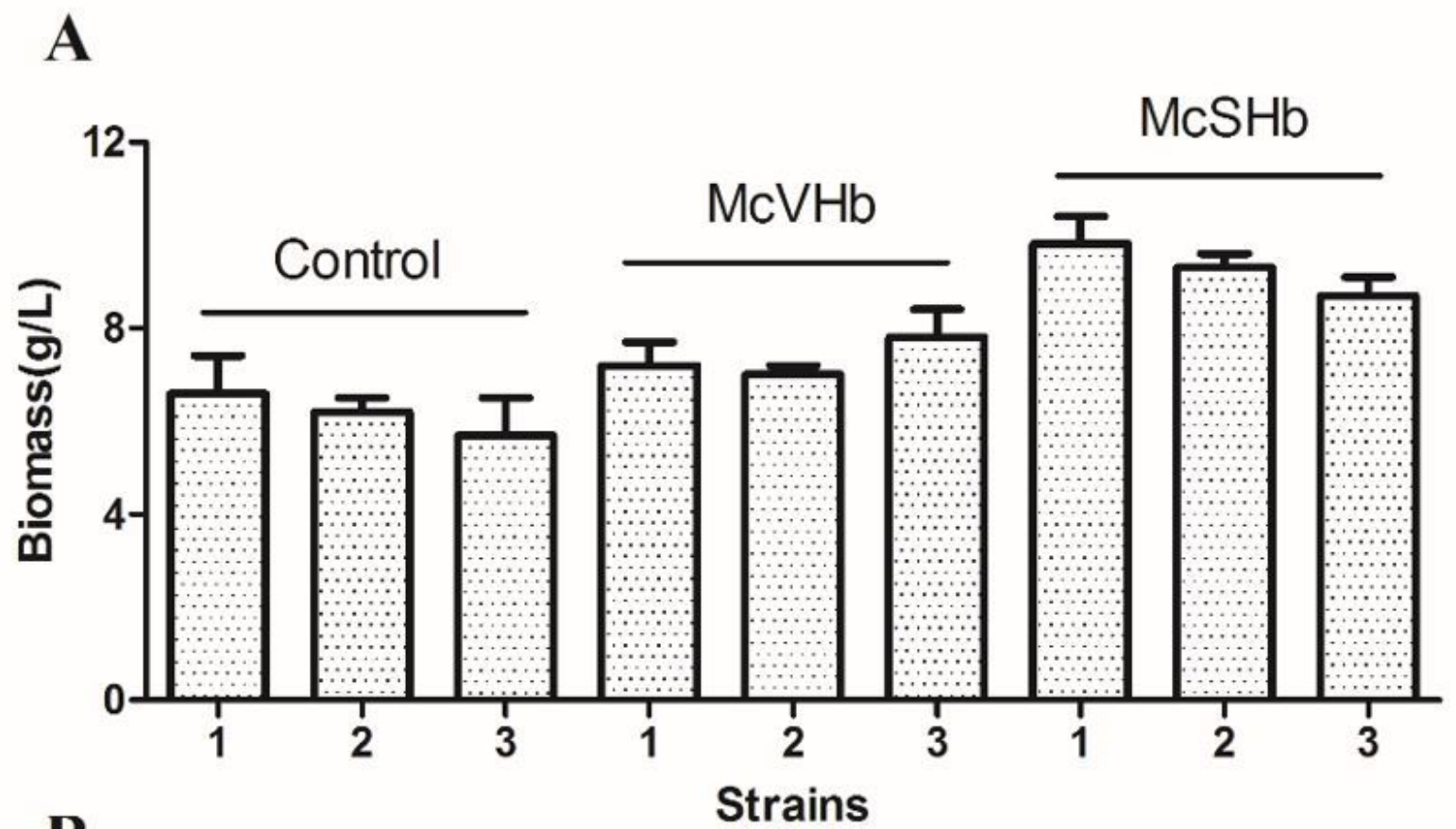

B

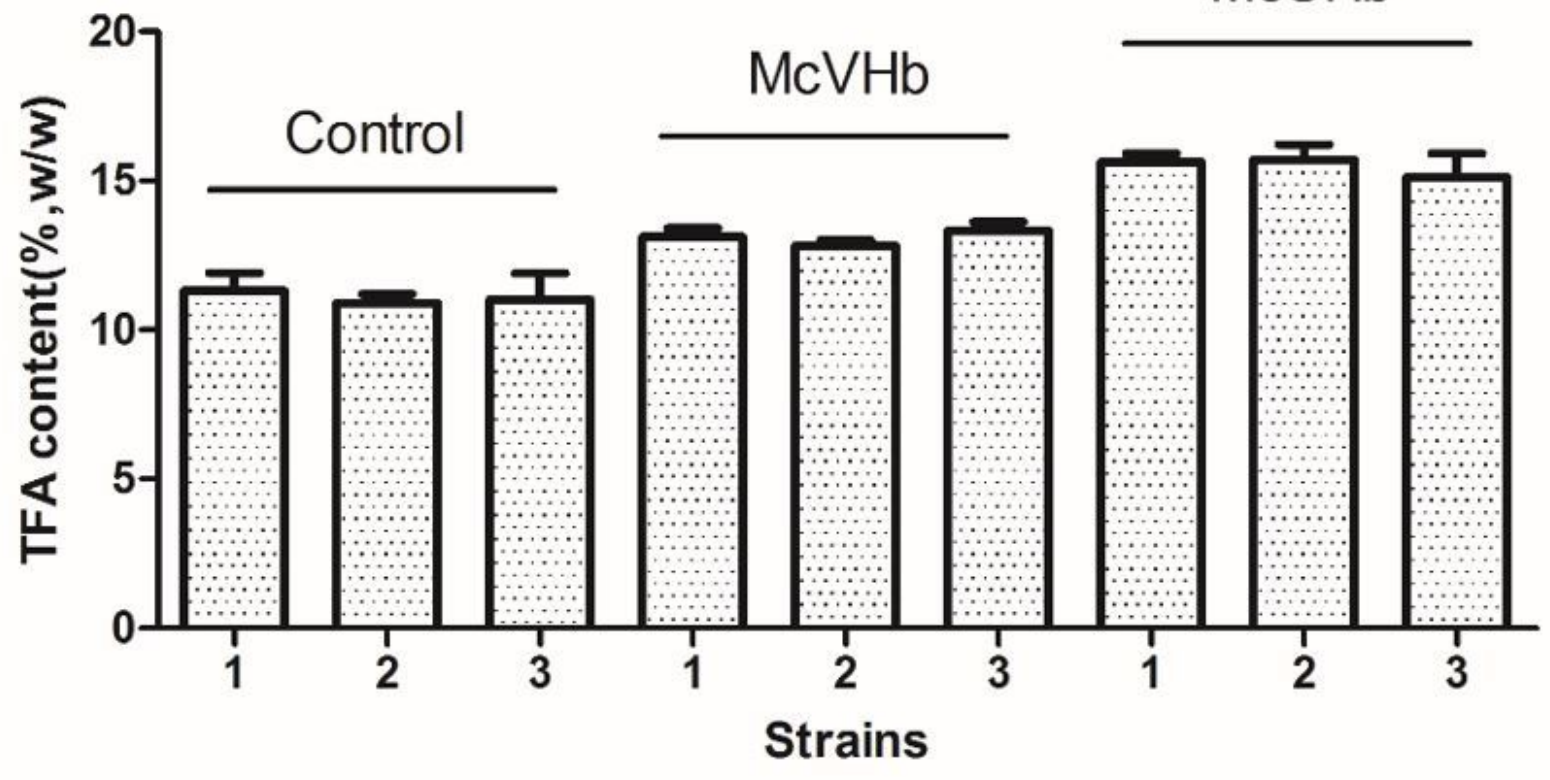

(Fig. 3)

Figure 3 
The biomass and TFA content of various transformants cultivated in flask. The transformants were cultivated in 1-L flask with modified K\&R medium $(200 \mathrm{~mL})$ for $96 \mathrm{~h}$, and then the mycelium was harvested to determine the biomass and TFA

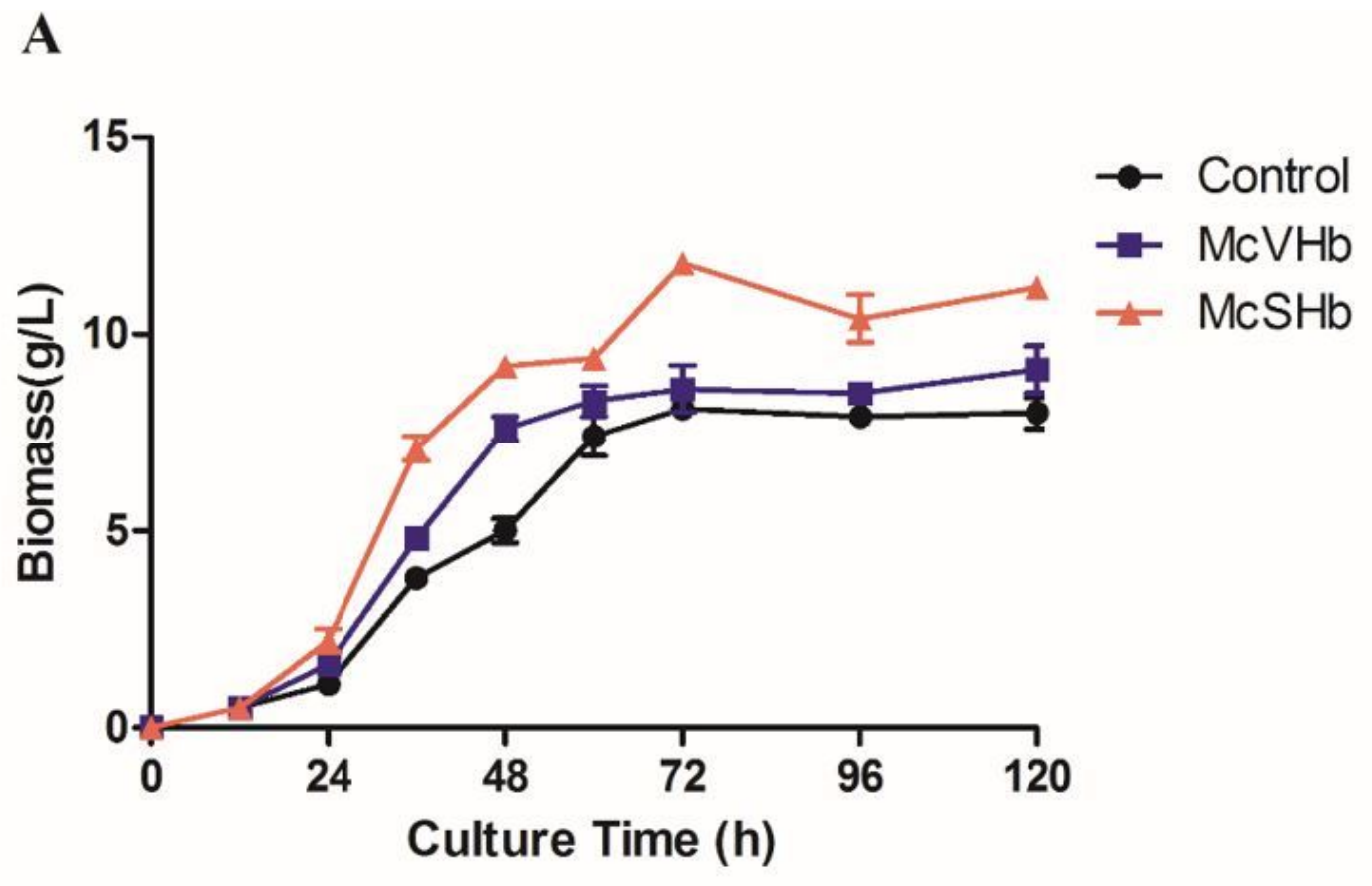

B

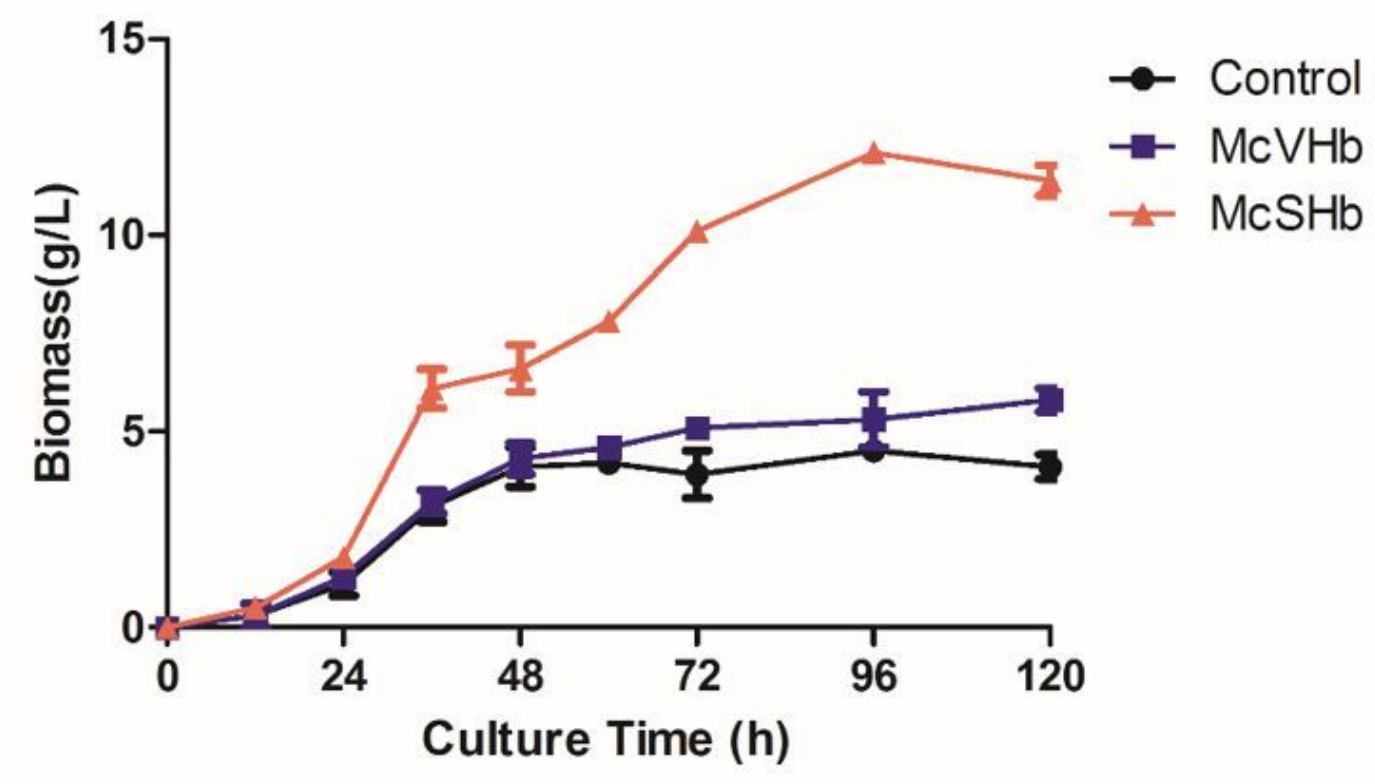

(Fig. 4)

Figure 4

The biomass of $\mathrm{McVHb}, \mathrm{McSHb}$ and the control strains cultivated in fermenter with aeration at $0.5(\mathrm{~A})$ and $0.2(\mathrm{~B}) \mathrm{vvm}$. 
A

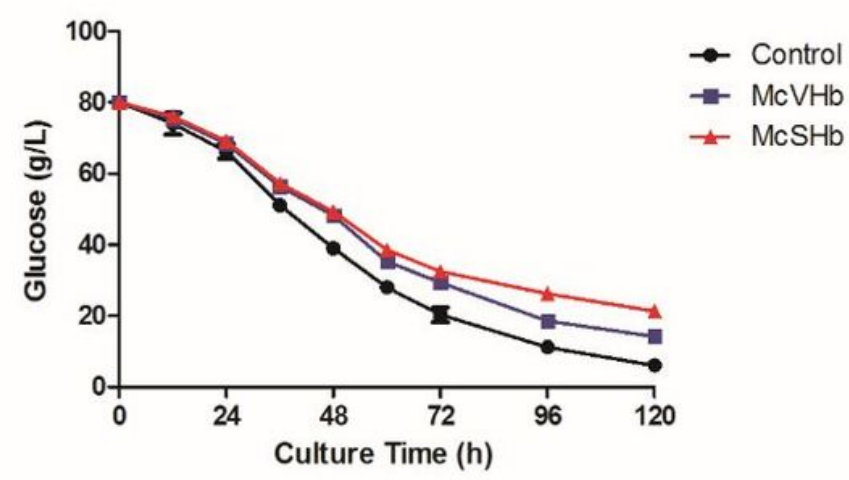

C

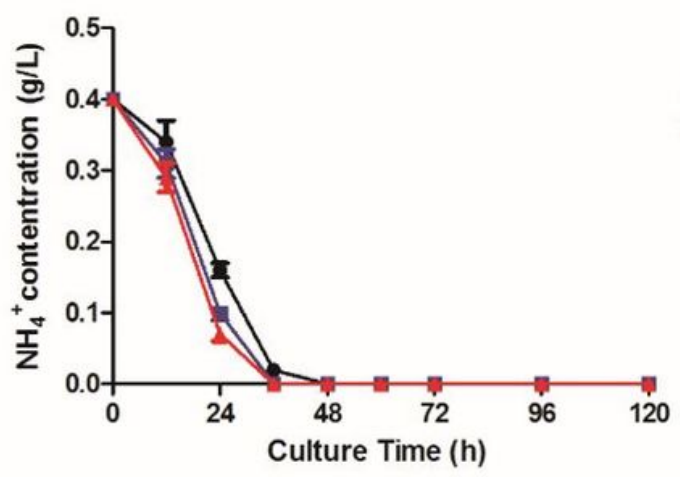

B

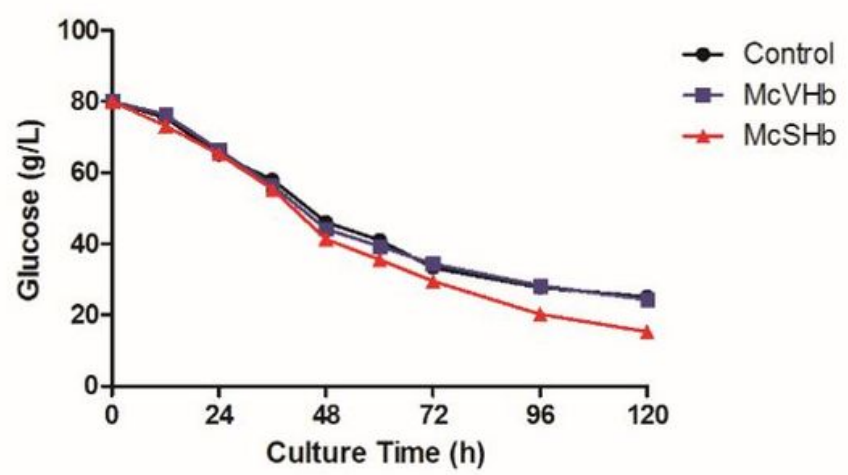

D

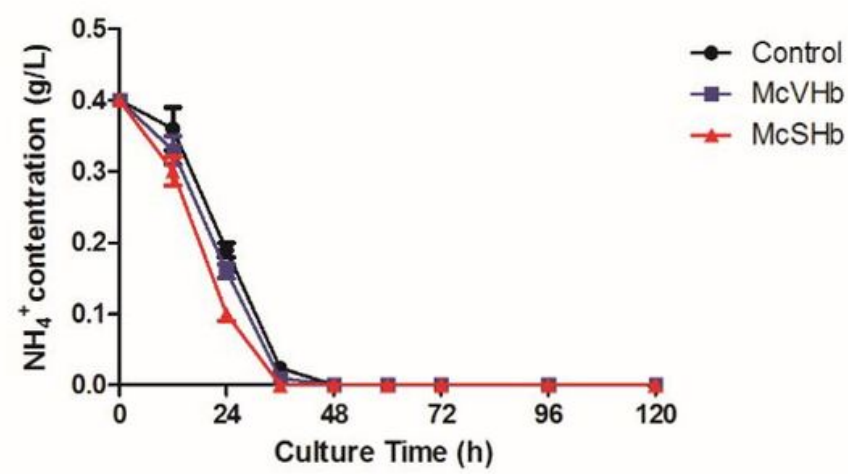

( Fig. 5)

\section{Figure 5}

The residual glucose and $\mathrm{NH} 4+$ concentration in the fermenter with aeration at $0.5 \mathrm{vvm}(\mathrm{A}, \mathrm{C})$ and 0.2 $\operatorname{vvm}(B, D)$. The mutant strains were grown in $2 \mathrm{~L}$ fermenter, and supernatants of medium were collected to detect the residual glucose and $\mathrm{NH} 4+$ concentrations in the medium according to the operational approach described in Methods. 


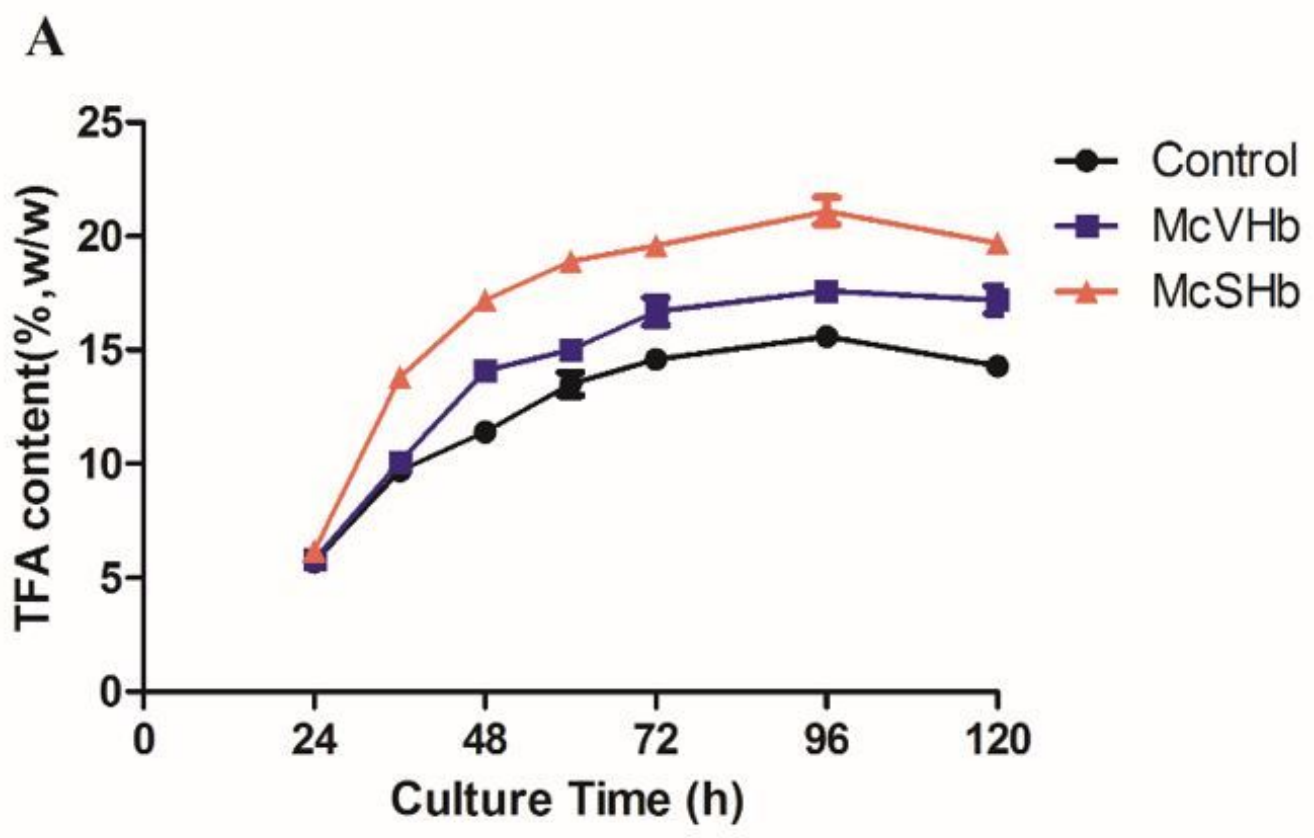

B

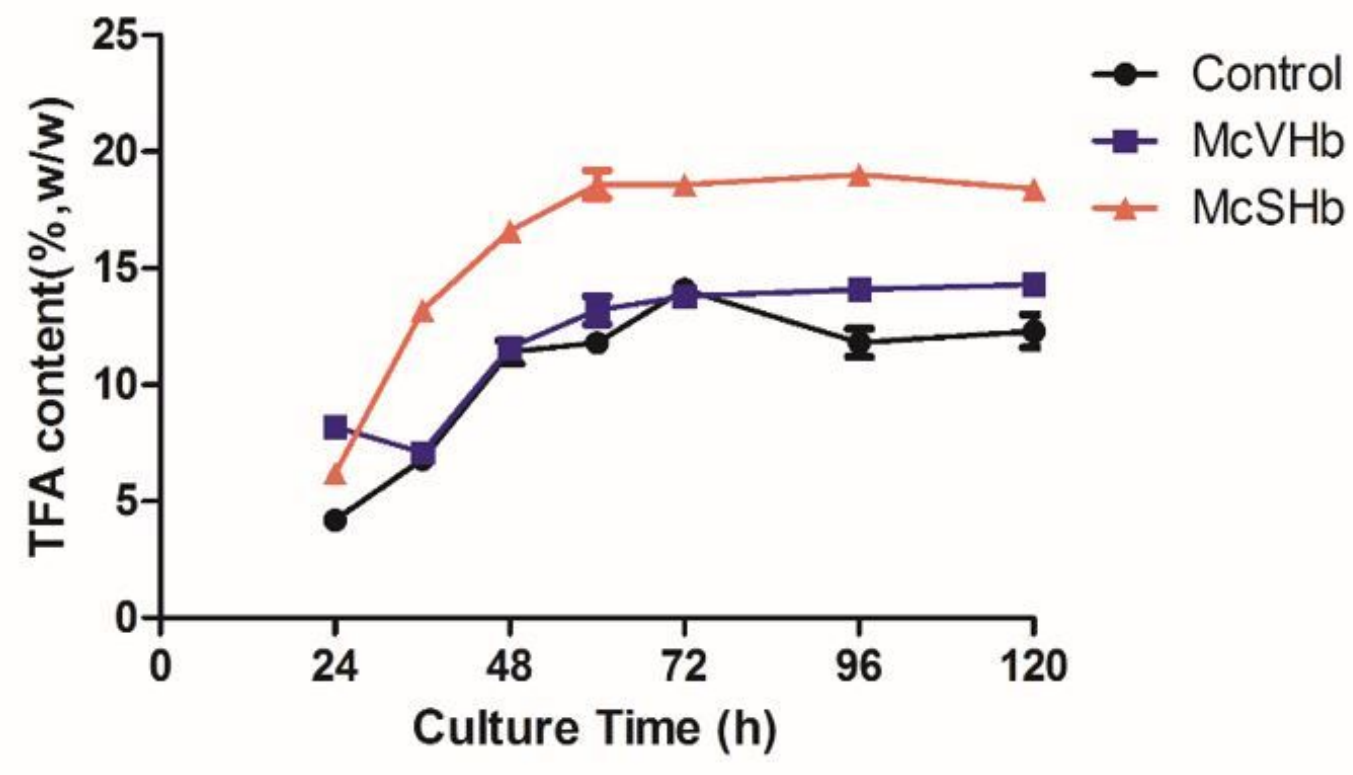

(Fig. 6)

Figure 6

The TFA content of McVHb, McSHb and the control strains cultivated in fermenter with aeration at 0.5 (A) and $0.2(B) v v m$. 